\title{
Helping scientists to write scientific English: challenges and issues
}

Ray Cooke

\section{(2) OpenEdition}

1 Journals

Electronic version

URL: http://journals.openedition.org/asp/1429

DOI: 10.4000/asp.1429

ISBN: 978-2-8218-0390-9

ISSN: 2108-6354

Publisher

Groupe d'étude et de recherche en anglais de spécialité

Printed version

Date of publication: 30 December 2002

Number of pages: 27-35

ISSN: 1246-8185

\section{Electronic reference}

Ray Cooke, «Helping scientists to write scientific English: challenges and issues », ASp [Online], 37-38 | 2002, Online since 15 July 2010, connection on 08 January 2020. URL : http://

journals.openedition.org/asp/1429; DOI : 10.4000/asp.1429

This text was automatically generated on 8 January 2020.

Tous droits réservés 


\title{
Helping scientists to write scientific English: challenges and issues
}

\author{
Ray Cooke
}

1 In response to the need to provide better language training for future professionals, the range of higher education institutions in which English language teachers now work is vast and it is unlikely that this tendency will change in the near future. More and more professionals must write in English, mainly (but not only) for research purposes. In the university setting in France, it is becoming increasingly common for the appointed teachers of English to be called upon by their faculty colleagues in other disciplines to help them write in English. The need to publish in English is now great at all levels of research, and even fledgling researchers in their first year of doctoral studies have much to gain from being the first-named author of a paper. While this aspect of the process has been widely discussed elsewhere, little is known about the implications for the English language teacher of providing such help. What sort of help may be given? How may this be done in logistic terms? How may the language specialist acquire sufficient knowledge of a particular discourse community's discourse to be able to offer help? Can such help have a lasting pedagogical value, and if so, can the help be recorded in some way for posterity? Finally, what broad range of research issues in applied linguistics does this raise? This paper discusses these issues in the light of the experience gained over the last twenty years in one language centre.

\section{One centre's experience}

2 The starting point for this story was a call received from the head of one of the university teaching hospital departments over twenty years ago. Intrigued by a fine point of a recently published article in a prestigious medical journal, he had blithely sent a letter (in English) to the editor of that journal, in which he offered an explanation for the physiological phenomenon described in the initial article. Nobody had checked the letter other than his secretary, who had typed it. However, great was his surprise to receive the 
editor's reply, i.e., scientifically the point made was of great interest, but the letter itself was so poorly written that it could not be published. Therefore, it needed checking and our team was called in to do it. Since then, of course, anecdotes like this have become part of common lore in research departments throughout our university (and no doubt elsewhere), and it is now frequent even for DEA (pre-doctoral) students to be aware of the need to write English collegially. This is testimony to the progress made over a twentyyear period in appreciating the value of writing scientific English correctly.

Moreover, two decades ago, French scientists behaved somewhat differently from the way they behave today. For example, if any publications were written in English, they would usually be produced by researchers from the "hard" sciences such as medicine, biochemistry and biology. ${ }^{1}$ Only more recently have researchers from "softer" disciplines begun to experience the need to write more frequently in English; although reading the academic press in English, their discourse communities (apart from a few exceptions) were for many years almost entirely Franco-French, so it is not surprising that they did not write in English. They did not need to. Another trend twenty years ago was for the boss (and frequently only him) to be seen to publish or communicate orally in English. This gave him the national/international kudos required to "exist" scientifically, while his colleagues remained "back home" in the department/laboratory and accomplished the groundwork. He would then report back to the rest of the team about the latest developments taking place in their particular field. This situation has radically changed for a number of reasons, as we will see later.

When questioned about how they managed to get by in English at that time, many researchers reply that they resorted to a variety of ploys including, and sometimes combining, the following: sending texts to English-speaking colleagues abroad (if they were sufficiently acquainted with any to request that sort of assistance); asking visiting lecturers/professors to do the job - yet the latter are typically willing to do it once or twice but not on a regular basis; or calling informally upon English teachers they knew but who were not necessarily acquainted with English for technical purposes. The result could be a feeling of disappointment arising from the following: the impression that they could not always convey their precise meaning; frustration due to the inordinate amount of time that it might take in getting their ideas into a form acceptable for submission, let alone publication; and disgruntlement born of the feeling that they were simply not competing on the same terms as native English speakers. Even so, when our department officially launched a system whereby researchers in the university could consult a member of our team for a one-to-one session of text editing, ${ }^{2}$ the number of requests was still limited. This was probably due to a lack of awareness of the system's existence, but probably more to the top-down organization of the departments/laboratories described above, i.e., only the bosses coming for help because a) they were the ones who published, and $b$ ) the system was not free of charge. ${ }^{3}$ Since then, the level of requests has increased exponentially as an increasing number of research teams have experienced the growing need to publish in English.

\section{The near future}

Moreover, this phenomenon is likely to continue to grow for a number of reasons. First, it is no longer possible (or desirable) for one research director to concentrate all the research efforts of his/her laboratory around him/herself. In some areas of study, it has 
become difficult to attract good students to the research profession, because there can be no guarantee of a job at the end of the long and painstaking process that doctoral study represents, while the selection process can be so severe. Some students shun the prospect of at least three years poorly paid hard grind, with no certainty of a job at the end. For this reason, it has become preferable to push young doctoral students to the fore by getting them to publish very early in their career so that their record of accomplishment should be as impressive as possible. This means earmarking funds to help them to publish in English. Second, a research team now tends to be judged not only by its excellence in one particular domain but also by the number of research themes in which it excels. Since no single researcher can be involved in every project, it has become preferable for the research bosses to delegate responsibility for projects to a number of team members, all of whom must publish in English. Third, many state-of-the-art research projects require multiple technological means and involve many co-workers, some of whom have much to gain from publishing in their own right. Fourth, budgetary restrictions in recent years have meant that resources must be pooled. The decision to assign resources to one team and to take them from another is made on the basis of a number of criteria, including the volume of articles published in peer-reviewed international journals. Finally, any successful research team finds itself in an enviable but ruthless loop, i.e., more published research generates more research credits, but with the obligation to produce even more research. In such a setting, the demand for text editing assistance from languageteaching colleagues can only increase.

\section{The impact on the ESP practitioner and the requesting party}

6 What impact has this twenty-year development had on the people involved in the process? For any language centre that wishes to undertake such work, there are a number of advantages. First, playing a role in the drafting of the research carried out by the institution has a positive repercussion on the degree to which the language teacher becomes one of its fully integrated members. No longer is the language teacher considered (no doubt, wrongly so) as a peripheral member of the teaching staff, with all that that entails. This danger is less apparent in institutions where the language teacher only teaches the English of one subject, e.g., medicine, because such colleagues largely play a fully satisfying role with regard to their colleagues. However, the problem can be more acute in language centres called upon to meet all the statutory teaching requirements of the institutions to which they belong. Second, becoming conversant with the work performed in the laboratories has an incontestable impact on pedagogical practice. One of the major procedural problems raised by novice ESP teachers is the very comprehension of the discourse of the subject that they are requested to teach. Of course, the professional literature contains many examples of the whys and wherefores of sound pedagogical practice in ESP, e.g., Hutchinson and Waters (1987), Dudley-Evans (1995a, 1995b) and Johns (1995). On the other hand, there can be no single answer to the question "What does all this technical jargon mean?" Helping researchers to write their articles can be one way of finding out. Third, synergies are created between requester and requested party, and may lead to the creation of new training courses in ESP. Typically, these courses are situated at doctoral level and involve both written and oral 
communication skills for scientists. The challenge then is to customize courses for highly demanding populations.

There are many advantages for the researchers. First, working in this way creates a form of language awareness that they would otherwise not have. Their English improves from one text to the next, they become more autonomous in their approach to the language and they learn (together with the language teacher/text editor) how to avoid a certain number of pitfalls that would otherwise delay publication of the article or even lead to its refusal, e.g., non-respect of instructions to authors, non-observation of language conventions, etc. However, these apparent truths still need to be proved scientifically by applied research on specific subpopulations, text genres, etc. Indeed, more generally, these synergies considerably widen the scope for applied linguists wishing to study a research object from within. This subject will be returned to later.

\section{Text editing: what it entails}

Until now, this article has discussed background issues to the subject of helping scientists to write their papers. We will now turn our attention to the job itself and what it entails. In any text editing session performed classically in a one-to-one situation (but see below), the text editor will have one overriding consideration in mind: to get reading committee approval of the manuscript in question and therefore to gain acceptance for publication. This may be more or less difficult according to certain factors. For example, if the researcher is reporting new findings that tend to refute what is widely held to be the truth in the speciality, the barriers to be crossed will be numerous. On the other hand, an invitation to write a review article for a journal will normally be accompanied by considerable largesse in the criteria of acceptability, although this may not always be the case. The genre therefore influences this issue. Another issue is the journal's impact factor. ${ }^{4}$ This internationally recognized factor reflects the weight that the journal is considered to have worldwide. The higher the factor, the greater the difficulty of getting an article published, although this may not necessarily be true, either. In any respect, it is essential for the text editor to be aware of the journal to which the article is to be sent, if only to know which set of instructions to authors should be used and which variant of the English language is recommended. Much precious time can be wasted if this sort of information is not known at the outset. ${ }^{5}$

The text editor must therefore take into account a range of factors that include instructions to authors, house style, the need for concision, and the grammar and syntax of the article he is working on. However, it is not sufficient to content oneself with the surface features of the text. Some novice researchers may be unaware of the discourse moves inherent in the discourse genre they are trying to master, with the result that whole sentences may appear in the wrong section or paragraph of the article. Awareness may therefore be drawn in passing to discourse models, and this may form the basis for a pedagogical spin-off in the form of a customized course for young researchers of a particular discipline, e.g., biology.

10 The overall aim will be to create and validate a version that is acceptable to the reading committee, probably providing certain modifications are made. A response from the journal's editor stating that the article is accepted, providing modifications are made, is to be considered as a success. It is then advisable for the text editor to validate the final 
version of the text that is sent back to the journal, in order to be sure that no new language errors or inadequate expressions have crept into it in the meanwhile. This is a permanent danger in multicentre studies where all the participants are obliged to sign a common form saying that they have read the manuscript and agreed with its final version: the temptation is of course for each one to add his final "touch" to the text, of which the English language text editor is unaware.

\section{Changes over the years}

11 As the years have passed, the service that our language centre offers to the members of our university has changed. With the increasing volume of work that this entails, a future development will be for section directors (e.g., head of English for sociology) to become responsible for text editing done in their sections. This will have the dual advantage of sharing the workload and providing valuable pedagogic input for future teaching programmes. However, this development can come about only if those ESP practitioners are aware of the conventions of the discourse community whose English they are teaching, and at all of its levels. It is simply not sufficient to correct surface features such as lexis and grammar since much more is involved.

12 Another evolution has been the increasing use of telecommuting. This has several advantages. First, it frees the text editor from the need to work in the presence of the author of the text. This would seem to be a drawback in one sense since the author is no longer present when the modifications are made, so is not at first sight in a position to ask questions about the changes made to his text. However, it is possible to "dialogue at a distance" by using the text-editing feature in Microsoft Word, preferably the latest version, which shows comments in the column on the right of the text but which, for technical reasons, cannot be displayed in this article. Moreover, this gives the text editor more time to think about the changes that he intends to make, and to do the work at 2 a.m., if he so desires! In addition, it provides both the requester and the text editor with a trace of what went on in the editing session, which in turn offers much scope for pedagogical spin-offs. Here is an example of an original version sent by a researcher with comments added by the text editor:

We hope we have now met the requirements of the referees. to fulfill all the comments of the referees. We are looking forward to hearing from the status of the manuscript you and thank you for your reply.

13 Alternatively, some text editors might want to combine the advantages of keyboarding and being present with the author of the article, although this does pose the logistic problem of sharing the same screen. A luxury would be to network on two screens in the same room.

\section{Research openings}

As time goes on, any text editor constitutes a corpus of texts that he has worked on, thus representing a wide range of research possibilities with regard to linguistic, cultural, didactic and technologic aspects. The scope is vast because of the permanent trace that can be kept of any work session, added to the fact that this form of data can easily be 
made comparable from site to site, thereby increasing considerably the size of corpora that may be analyzed or the number of subjects to be compared.

In linguistics, some of the areas of study are the following. First, there is the analysis of the discourse produced by various discourse communities to see whether there are any divergences and similarities. The study by Birch (Birch 1996) showed that Francophone scientists produce a common core of L2 interference errors when writing English, but the focus concerned only life sciences researchers at one point in time. However, language evolves, as do the empirical rules governing its use; for example, in a certain subspeciality of plant biology that is well represented in our university, it has become commonplace for researchers to announce their final hypotheses in the introduction of their articles. Corpora analysis might throw light on newly generated metalinguistic criteria that have become acceptable to that discourse community. Second, there is the question of the presence of the text editor in the final published text. To what extent is He visible and how much and where has He attempted to impose/protect the canons of the English language? This in turn raises other issues such as the power that the text editor wields and its correct usage, the necessary interdependence (and its management) between the non-native-speaking researcher and the text editor, the acceptability of Englishes other than the all-powerful British and American versions, etc. In addition, the above-mentioned themes are all strongly pervaded by cultural considerations, so research into any of them will probably focus on linguistic factors and cultural identities in a combined approach.

The didactic perspectives are far-reaching. As stated earlier, one of the major procedural issues frequently raised by language teachers called upon to teach ESP is: how can I be expected to teach the language of something I do not understand? That question in turn subtends the other wider issue to which this article has drawn attention: this form of understanding can come about only if the ESP practitioner attempts to grasp the linguistic and rhetorical conventions of the discourse community. As time goes on and the need for text editing increases, many colleagues are likely to take a plunge into the unknown and begin to edit texts for their faculty or institutional colleagues. They will then discover three considerable advantages: first, they will begin to gain an understanding of the specialties concerned far surpassing their initial understanding; second, they will extend their knowledge of discourse conventions; third, they will consequently be in a position to perform fresh needs analysis for their students. Herein lies the possible focus of future didactic research deriving from text editing. One of the main achievements in ESP in France in the last twenty years has been to frontline communicative skills, and there can be no doubt of the soundness of this policy. On the other hand, this is not enough in itself and there is a need to educate in the ins and outs of technical discourse those of our learners who will conceivably need such knowledge in the near future. In other words, text editing might lead to action research projects aiming at redefining the changing needs of learner groups at the various stages of their academic careers. This would no doubt have the knock-on effect of optimizing resources at a time when it is becoming more and more difficult to earmark funds for language learning. Moreover, another direction already being taken by some (see Williams et al. in this volume) is the design of computer-assisted tools for helping researchers to write. Once available, such tools could be investigated for their pedagogical use. 


\section{Parallel issues}

17 A final procedural issue is whether this type of work actually should be remunerated or not, and if so, on what basis. This may seem like a non-issue in some parts of the world. For example, in Scandinavian countries, there is much awareness of the need for research to be written up properly and of the considerable amount of work that this entails, so universities earmark funds to recruit linguists whose sole task is the technical editing of research articles. However, in France, no such arrangement exists officially on a national basis since text editing is not considered part of the pedagogical acts that teachers are mandated to perform, so each institution finds its own solution: relying on a nativespeaking research fellow; having recourse to a service such as ours; outsourcing; calling upon friends, etc.

18 Although these various pathways generally lead in the long run to success (as defined by publication of the article, albeit in a journal with a lesser impact factor than perhaps initially hoped for), there are as yet no standard specifications of what the conduct of both "contracting" parties should be. For example, in the event of a refusal for substandard English of an article validated by a text editor, should the "after-sales service" be considered as part of the initial "agreement" into which the "contracting parties" entered, and therefore not be subject to any further form of remuneration? At first sight, the answer to this question might reasonably be in the affirmative. However, what if the text has been modified, perhaps substantially, since the last time it was checked by the text editor? Alternatively, what if it can be easily demonstrated that the English of those who judge the text to be linguistically inadequate is itself of dubious value, thereby casting aspersions on the very process of review? For this reason, it would seem that there is need for a type of charter which would clarify some of the "fuzzier" issues that may arise throughout the editing process, so that colleagues wishing to launch out into this area have some terms of reference to which they can peg their own expectations.

\section{The longer-term future}

Peer review takes time, sometimes too much. Time is costly for a scientist. Paper and printing cost money. Postage is expensive. For these reasons, the reader is invited to imagine a scientific world in which the main stakeholders (i.e., the scientists who produce the research) decide in common to short-circuit the traditional publishing channels and to take matters into their own hands, i.e., communicate without the traditional vector of printed paper. A farfetched scenario? In fact, that new world is already upon us in a number of different forms. For example, driven by the pressure to communicate pertinent new information as early as possible, a number of general medical journals ${ }^{6}$ now have full text online versions. Even more remarkable, the Journal of Biological Chemistry $^{7}$ has gone as far as to suppress the traditional peer review process and to replace it with a system run exclusively by the editorial board, the actual review process normally being conducted by only one person. In this way, newly accepted manuscripts may be published continuously in the "papers in press" section of the journal ahead of the paper version but not yet in copy edited form. Perhaps the most striking manifestation of this empowerment of the main stakeholder is in the field of informatics, 
where researchers regularly put their articles on their web sites, even if they are in the process of being printed in a paper version; the issue of copyright is simply sidestepped.

There could be objections to this new order. How would it be possible to decide who has the best curriculum vitae because some of the work performed would not be published through traditional channels? How, therefore, could researchers lay a claim to promotion? The answer is that academic credit would doubtlessly be gained by the number of hits that a researcher's web site or archive would receive. In that way, the members of a discourse community would instantly be aware of who is doing the most innovative work. Herein lies the crux of the matter; scientists in a discourse community are more or less able to understand each other's written English even if it infringes many of the sacrosanct rules of the language. Why should they therefore take pains over the formal presentation of their work to the rest of their own discourse community when their meaning is very largely understood? The considerable number of errors in professional e-mail is probably another manifestation of this. Moreover, Microsoft PowerPoint has become the common medium of scientific communication. LaPorte et al. (2002) draw attention to the fact that it is "disability-friendly", relatively inexpensive and that scientists control production, not professional journals. They foresee a world in which scientists, especially non-native speakers, will circumvent the need to learn what they term "journal speak", will not see their work blackballed for "bad English" and will save large sums of money hitherto earmarked for publishing costs, simply by posting PowerPoint presentations on the net. They even point to the possible demise of the IMRAD canon.

What could the consequences of this trend be for our discourse community, the ESP practitioners and text editors whose role is to help non-native-speakers to publish? Are we to continue as we have until now, focusing not only on surface features but also on discourse conventions that pose problem? Alternatively, will we be obliged to find a number of "fixes" in a "quick and dirty" world of scientific communication? The answer probably lies between the two. While there has been no sign of any downturn in our institution in the number of requests for editorial help, there has recently been an upswing in the number of projects to be completed urgently. This means that the authors are becoming increasingly overloaded in their routine work and are finding it difficult to meet deadlines; or that the deadlines themselves are becoming stricter and that the pressure to publish quickly is increasing. This subject certainly requires further investigation since it may ultimately have repercussions on both the pedagogical and text editing objectives pursued by ESP practitioners.

\section{BIBLIOGRAPHY}

Abbasi, K. et al. 2002. "Four futures for scientific and medical publishing". British Medical Journal $325,1472-1475$.

Amores, M. J. 1997. “A new perspective on peer editing”. Foreign Language Annals 30/4, 513-522. 
Birch, Susan. 1996. "Les besoins linguistiques des scientifiques français publiant en anglais : Analyse d'un corpus de premières rédactions et de leur correction". Doctoral thesis, Université de Bordeaux 2.

Cooke, R. 1999. "Structuring discussion writing: a fresh angle". British Medical Journal <bmj.com/ cgi/eletters/319/ 7209/580\#4455>.

Delamothe, T. 2002. "Is that it? How online articles have changed over the past five years". British Medical Journal 325, 1475-1478.

Docherty, M. \& R. Smith. 1999. "The case for structuring the discussion of scientific articles". British Medical Journal 318, 1224-1225.

Dudley-Evans, T. 1995a. "Genre models for the teaching of academic writing to second language speakers: Advantages and disadvantages". TESOL Journal France 2/2, Functional Approaches to Written Text: Classroom Applications, 181-192.

Dudley-Evans, T. 1995b. "Common-core and specific approaches to the teaching of academic writing”. In In Belcher D. \& G. Braine (eds.), Academic Writing in a Second Language: Essays on research and pedagogy. Norwood, NJ: Ablex, 293-312.

Gosden, H. 1995. "Success in RA writing and revision: A social-constructionist perspective". English for Specific Purposes Journal 14/1, 37-57.

Hutchinson, T. \& A. Waters. 1987. English for Specific Purposes - A learning-centred approach. Cambridge: Cambridge University Press.

Johns, A. 1995. "Teaching classroom and authentic genres: Initiating students into academic cultures and discourses". In Belcher D. \& G. Braine (eds.), Academic Writing in a Second Language: Essays on research and pedagogy. Norwood, NJ: Ablex, 277-291.

Laporte, R. et al. 2002. "Papyrus to PowerPoint (P2P): metamorphosis of scientific communication”. British Medical Journal 325, 1478-1481.

Nwogu, K. 1997. "The medical research paper: Structure and functions”. English for Specific Purposes 16/2, 119-138.

Peacock, M. 2002. "Communicative moves in the discussion section of research articles". System 30/4, 479-497.

Robb, T., S. Ross \& I. Shortreed. 1996. "Salience of feedback on error and its effect on ESL writing quality". TESOL Quarterly 20/1.

Swales, J. \& C. Feak. 1994. Academic Writing for Graduate Students: Essential tasks and skills. Ann Arbor, MI: University of Michigan Press.

Swales, J. 1990. Genre Analysis: English in Academic and Research Settings. Cambridge: Cambridge University Press.

\section{NOTES}

1. The Université Victor Segalen Bordeaux 2 is a life sciences university. It includes a wide range of "hard" sciences but also "softer" ones such as psychology, sociology, anthropology and sports sciences.

2. Done in handwriting by the team member. Therefore, no provision could be made for errors subsequently arising from erroneous transmission of the handwritten modifications by the 
researcher, or by his secretary. Clearly, the potential was high for adding extra errors where there may have been none before.

3. However, the first three-hour session with any tenured member of the university was given free, the team member being paid on a locally agreed basis.

4. The list of journals and their impact factors can be downloaded from the following address < http://www.mol.uj.edu.pl/modmol/LINKS/news/if99/if99.html>.

5. The present author recalls editing an article containing about 8,000 words. Much time and energy was spent in improving it, only to find out weeks later that it should not have exceeded 5,000 words!

6. Annals of Internal Medicine, British Medical Journal, Journal of the American Medical Association, The Lancet and the New England Journal of Medicine.

7. <http://www.jbc.org/>

\section{ABSTRACTS}

ESP practitioners in universities are increasingly being requested to edit their faculty colleagues' research manuscripts. This newly emerging relationship between text editor and requesting party involves a form of mediation that goes beyond the traditional relationship between teacher and learner. Providing the task is performed assiduously, ESP practitioners can only gain from this activity in terms of the improved input they are able to provide their learners. The paper discusses these issues in the light of one centre's experience and points to possible developments for the future.

Les enseignants LANSAD se voient sollicités de plus en plus fréquemment par leurs collègues non-anglophones pour réviser leurs manuscrits de recherche. Ce nouveau type de rapport entre réviseur et demandeur comporte une forme de médiation qui dépasse la relation traditionnelle entre enseignant et enseigné. À condition de s'investir pleinement dans cette tâche, les enseignants LANSAD ne peuvent que retirer un bénéfice de cette activité, grâce à l'aide améliorée qu'ils sont en mesure d'apporter à leurs apprenants. Cet article traite de ces problématiques à la lumière de l'expérience d'un centre et indique quelques développements futurs.

\section{INDEX}

Mots-clés: enseignant en LANSAD, rédaction, scientifique, révision de manuscrits

Keywords: ESP practitioner, scientist, text editing, writing

\section{AUTHOR}

RAY COOKE 